\title{
Visualização de Informação aplicada à compreensão de resultados de Recuperação de Imagens Baseada em Conteúdo
}

\author{
Davi Silva Rodrigues, Fátima L. S. Nunes \\ ${ }^{1}$ Laboratório de Aplicações de Informática em Saúde (LApIS) \\ Escola de Artes, Ciências e Humanidades \\ Universidade de São Paulo (USP) \\ São Paulo - SP, 03828-000 \\ \{davi.rodrigues, fatima.nunes\}@usp.br
}

\begin{abstract}
Information Visualization aims to represent abstract data graphically, improving their comprehension. Content-Based Image Retrieval (CBIR) systems yield large amounts of data that are frequently represented in a poorly comprehensible way. Considering this scenario, this article proposes and evaluates information visualization techniques that optimize the presentation of CBIR systems results. Two two-dimensional and three three-dimensional techniques were developed. By means of user evaluation, it was found that the two-dimensional techniques proposed were more efficient in improving the comprehension of the results in the context analyzed.
\end{abstract}

Resumo. A Visualização de Informação se propõe a representar dados abstratos graficamente, de modo a melhorar a compreensão dos mesmos. Sistemas de recuperação de imagens baseada em conteúdo (Content-Based Image Retrieval - CBIR) produzem grandes volumes de dados, que, muitas vezes, são exibidos de modo pouco compreensível. Tendo em vista este cenário, este artigo tem como objetivo propor e avaliar técnicas de visualização de informação que otimizem a exibição de resultados de sistemas de CBIR. Foram desenvolvidas duas técnicas bidimensionais e três tridimensionais. Por meio de avaliação com usuários, constatou-se que as técnicas bidimensionais propostas foram as mais eficientes em melhorar a compreensão dos resultados no contexto analisado.

\section{Introdução}

A Visualização de Informação (VI) estuda formas de representar informações graficamente, a fim de facilitar o entendimento, a percepção e a dedução de novos conhecimentos a partir das informações [Freitas et al. 2001]. A área de VI pode beneficiar a compreensão de dados em diversas aplicações como tabelas, gráficos, sinais de trânsito e códigos-fonte de software por exemplo [Dias e Carvalho 2007].

Os avanços da Computação tornaram possível a manipulação de grande quantidade e variedade de dados. Imagens, vídeos e músicas precisam ser armazenados e recuperados quando necessário. Entretanto, os sistemas de buscas baseadas em texto não são tão eficientes para esses tipos de dados. Isso ocorre porque a linguagem escrita é uma invenção humana e, portanto, os algoritmos de busca podem utilizar as estruturas e regras da linguagem. Os algoritmos de busca de imagens e vídeos processam pixels, que não têm "regras" e não possuem carga semântica isoladamente [Datta et al. 2008]. 
Sistemas de recuperação de imagens baseada em conteúdo (mais conhecidos como sistemas de CBIR - Content-Based Image Retrieval) utilizam o conteúdo das imagens, ou seja, texturas, formas e cores para definir a similaridade entre elas. Em geral, uma imagem é escolhida pelo usuário e comparada a cada imagem armazenada [Heesch 2008]. Como resultado, o usuário recebe uma lista de imagens ordenadas da mais semelhante (que é a primeira da lista) àquela menos semelhante à imagem usada como modelo.

Dessa forma, o usuário precisa analisar cuidadosamente os resultados, já que uma imagem classificada como menos semelhante pode ser a imagem que o usuário buscava. Isso é possível porque nem sempre o funcionamento do sistema de CBIR é conhecido pelo usuário, que acaba tendo dificuldades para formular buscas eficazes [Imo et al. 2008].

Aplicar técnicas de visualização de informação aos resultados de um sistema de CBIR pode tornar possível exibir tais resultados de maneira mais intuitiva. Adicionalmente, o funcionamento da busca pode ser explicitado, pois o sistema define a similaridade entre imagens por meio de dados abstratos (números representando texturas, cores, formas, tamanhos, etc.), que passam a ser representados de forma visual.

Apesar da grande quantidade de trabalhos disponibilizados na literatura sobre visualização de informação, apenas o trabalho de [Pinto-Cáceres 2010] desenvolveu visualizações aplicadas a CBIR apresentando três abordagens no domínio bidimensional. No entanto, como em geral os sistemas de CBIR trabalham com grandes volumes de dados, uma questão que merece investigação é se a visualização no domínio tridimensional proporciona melhor compreensão ao usuário.

O objetivo deste trabalho é propor e avaliar técnicas de visualização de informação que tornem mais intuitivo o entendimento dos resultados de um sistema de CBIR comparando técnicas nos domínios bidimensional (2D) e tridimensional (3D). Para tal, foram desenvolvidas cinco técnicas de visualização de informação. Cada uma destas formas de visualização foi avaliada por meio de testes com usuários a fim de determinar qual delas é a mais eficiente para facilitar a compreensão dos resultados.

O sistema de CBIR foi desenvolvido com base em um sistema de reconhecimento facial existente, que utiliza uma base de imagens faciais e dezessete extratores de cor, forma e textura [Bergamasco e Nunes 2011].

Além desta introdução, este artigo está constituído em mais quatro seções. Conceitos de visualização de informação e de CBIR são disponibilizados na seção 2. As técnicas de visualização propostas são descritas na seção 3. Os resultados obtidos com a avaliação dessas técnicas são apresentados e discutidos na seção 4. Por fim, na seção 5, são apresentadas as conclusões e as possibilidades de trabalhos futuros.

\section{Visualização de Informação e Recuperação de Imagens Baseada em Conteúdo}

A área de Visualização de Informação estuda representações visuais de dados abstratos. Desta forma, o entendimento desses dados pode ocorrer de modo mais rápido e simples. Existem diversas técnicas de visualização de informação. Elas podem ser divididas em dois grupos: as técnicas bidimensionais e as tridimensionais [Nascimento e Ferreira 2005].

As técnicas bidimensionais são as mais simples e incluem imagens, tabelas, dis- 
posição em grid, espiral, anéis concêntricos, gráficos bidimensionais, treemaps, entre outras. As técnicas tridimensionais são, em grande parte, variações das bidimensionais que adicionam profundidade ou reproduções de ambientes e/ou objetos reais.

Sistemas de CBIR permitem ao usuário especificar uma consulta e receber como resposta um conjunto de imagens semelhantes. A consulta pode ser textual, por meio de uma imagem modelo ou por meio de um esboço feito pelo usuário [Datta et al. 2008].

O conceito de semelhança, nesses sistemas, é representado por algoritmos e funções de similaridade. Os algoritmos são chamados de extratores e analisam determinadas características das imagens por meio de seus pixels. Eles atribuem um valor numérico para cada uma das características analisadas. O conjunto de características de uma imagem forma um vetor de características. As funções de similaridade determinam as distâncias entre as imagens de acordo com seus vetores de características. Quanto mais distantes duas imagens estão, menos semelhantes elas são [Torres e Falcão 2008].

Na literatura, existem muitos trabalhos sobre visualização de informação. Entretanto, poucos são os trabalhos que abordam os benefícios de aplicar técnicas de visualização em sistemas de CBIR. A Tabela 1 apresenta as principais técnicas de visualização encontradas na literatura em ordem cronológica. A última coluna indica se a técnica foi aplicada para facilitar a compreensão de resultados de sistemas de CBIR.

\begin{tabular}{|c|c|c|c|c|}
\hline Técnica & Tipo & Domínio & Referência & CBIR \\
\hline $\begin{array}{l}\text { Gráfico de } \\
\text { Dispersão }\end{array}$ & $2 \mathrm{D}$ & - & [Godinho et al. 2007] & Não \\
\hline $\begin{array}{l}\text { Perspective } \\
\text { Wall }\end{array}$ & $3 \mathrm{D}$ & Dados lineares & [Ltifi et al. 2009] & Não \\
\hline $\begin{array}{l}\text { Imagens e } \\
\text { Texto }\end{array}$ & $2 \mathrm{D}$ & Arquivos binários & [Grégio et al. 2009] & Não \\
\hline Grid & $2 \mathrm{D}$ & Imagens & [Pinto-Cáceres 2010] & Sim \\
\hline $\begin{array}{l}\text { Anéis Con- } \\
\text { cêntricos }\end{array}$ & $2 \mathrm{D}$ & Imagens & [Pinto-Cáceres 2010] & Sim \\
\hline Espiral & $2 \mathrm{D}$ & Imagens & [Pinto-Cáceres 2010] & Sim \\
\hline Metáfora & - & - & [Chau 2011] & Não \\
\hline Diversos & $2 \mathrm{D}$ & Dados da Web & [Dörk et al. 2012] & Não \\
\hline Diversos & $3 \mathrm{D}$ & $\begin{array}{l}\text { Reservatórios de petró- } \\
\text { leo/gás }\end{array}$ & [Hipp et al. 2013] & Não \\
\hline $\begin{array}{l}\text { Gráficos } \\
\text { bidimensi- } \\
\text { onais }\end{array}$ & $2 \mathrm{D}$ & Dados numéricos & [Yang et al. 2014] & Não \\
\hline $\begin{array}{l}\text { Cubo de re- } \\
\text { gressão }\end{array}$ & $3 \mathrm{D}$ & Dados numéricos & [Chan et al. 2014] & Não \\
\hline $\begin{array}{l}\text { Árvores de } \\
\text { objetos }\end{array}$ & $2 \mathrm{D}$ & Processos empresariais & [Somanath et al. 2014] & Não \\
\hline
\end{tabular}

Em [Chau 2011] são apresentadas metáforas como formas de visualização de resultados da web. As metáforas são definidas como objetos gráficos que representam valores multidimensionais. O autor conclui que metáforas apresentam um bom desempenho 
quando representam características e metadados complexos. Em [Pinto-Cáceres 2010] foram desenvolvidas visualizações que evidenciam grupos de imagens formados a partir de técnicas de CBIR. As três técnicas apresentadas organizam os resultados da busca em grupos e subgrupos utilizando círculos e espirais. Em [Ltifi et al. 2009] os autores indicaram os pontos positivos e negativos e classificaram diversas técnicas de visualização quanto à quantidade de dimensões e quanto ao tipo de dados representado, observando aspectos técnicos e com foco na interação com o usuário e na sua participação no processo de KDD (Knowledge Discovery from Data).

[Grégio et al. 2009] fizeram uma compilação de técnicas de visualização de duas e três dimensões que podem ser aplicadas em dados de redes de computadores. O objetivo dos autores foi avaliar tais técnicas quanto à análise de $\log s$ de equipamentos de rede, de modo a facilitar a busca de informações relevantes em grandes volumes de dados. Em [Godinho et al. 2007] foi criada uma ferramenta de visualização de dados multidimensionais, permitindo aos autores relacionar diferentes formas de visualização das mesmas informações com a finalidade de permitir ao usuário entender melhor as relações entre as imagens da base pesquisada.

Mais recentemente, [Dörk et al. 2012] propuseram uma técnica de visualização interativa com o objetivo de propiciar uma nova forma de navegar na Web. A proposta dos pesquisadores visa a oferecer visualização de forma gráfica e permitir a formulação de questões de consultas. A visualização gráfica é bidimensional e inclui mecanismos de seleção de dados, mapas geográficos, nuvem de tags, mecanismos de visualização em forma de árvores e um local para digitação de queries para consultas. Um framework para facilitar a visualização de informação de processos em empresas é apresentado em [Hipp et al. 2013]. O framework proposto oferece visualizações de árvores de navegação semântica que apresentam conexões entre os objetos, permitindo ao usuário verificar como os processos se interligam.

[Yang et al. 2014] conduziram dois experimentos para estudar e compreender as preferências das pessoas com a finalidade de compor visualizações. Os autores desenvolveram um framework que ajuda usuários a combinarem duas ou mais técnicas para fornecer uma visualização integrada de informação, usando metáforas de gráficos no domínio bidimensional. Em [Chan et al. 2014] é apresentado o cubo de regressão, que consiste em uma extensão tridimensional dos gráficos scatterplots, comumente empregados para visualizar dados multidimensionais. No proposta apresentada, o scatterplot possui três faces nas quais as correlações entre duas variáveis são exibidas considerando linhas de sensibilidade. Além da técnica de visualização citada, a proposta inclui técnicas de interação para realizar operações como agrupamento e seleção de dados.

Considerando domínios mais específicos, [Somanath et al. 2014] apresentaram um conjunto de visualizações 3D interativas, projetadas para explorar modelos de pósprocessamento de simulação de reservatório de petróleo e gás. Três tipos de visualizações, denominadas pirulito, círculos de informação e indicadores de caminho, apresentam informações específicas de trajetórias em diferentes formatos visuais. Segundo os autores, as técnicas podem ser usadas para explorar trajetórias de poços de petróleo existentes, bem como planejar futuros poços. 


\section{Técnicas de visualização propostas}

As técnicas de visualização encontradas na literatura (Tabela 1) são, em sua maioria, bidimensionais e não tornam explícitos os critérios utilizados pelo sistema para definir a semelhança entre as imagens.

Visando à comparação entre técnicas nos domínios bidimensional e tridimensional, este trabalho propõe cinco técnicas de visualização aplicadas a resultados de sistemas de CBIR. As duas técnicas no domínio bidimensional (visualização bidimensional linear e em espiral) foram implementadas com base nas técnicas de anéis concêntricos e espiral apresentadas em [Pinto-Cáceres 2010]. As outras três técnicas no domínio tridimensional (visualização tridimensional linear, em espiral e em cone) foram implementadas com o propósito de fornecer uma perspectiva tridimensional às técnicas bidimensionais citadas.

\subsection{Extratores de características}

O sistema de CBIR original permite que o usuário faça buscas em uma base de imagens faciais a partir de uma imagem modelo. Adicionalmente, permite que o usuário forneça seu feedback sobre a classificação realizada. Este retorno do usuário é utilizado para o aprendizado do sistema a fim de melhorar os resultados das buscas. Desta forma, o sistema passa a considerar também a opinião do usuário ao classificar as imagens da base pesquisada [Bergamasco e Nunes 2011]. Por meio de uma interface gráfica, o sistema permite ao usuário fazer buscas em uma base de imagens faciais 1 , que dispõe de 400 imagens de faces (duas imagens de cada pessoa). Deve ser salientado, entretanto, que as técnicas de visualização propostas aplicam-se a qualquer conjunto de resultados de sistemas CBIR.

Foram utilizados os mesmos dezessete extratores de características do sistema original, que podem ser divididos em extratores de cor, textura e forma [Bergamasco e Nunes 2011].

Os extratores de cor são:

- Média do histograma em nível de cinza: determina se a imagem é mais clara ou mais escura.

- Média do histograma considerando os canais de cores Red Green Blue (RGB): determina se a imagem é mais clara ou mais escura, considerando cada canal de cor separadamente.

- Desvio padrão do histograma em nível de cinza: determina o índice de variação de cores da imagem.

- Desvio padrão do histograma em RGB: determina o índice de variação de cores da imagem, considerando cada canal de cor separadamente.

- Obliquidade do histograma em nível de cinza: determina a variação das cores da imagem.

- Obliquidade do histograma em RGB: determina a variação das cores da imagem, considerando cada canal de cor separadamente.

- Média dos pixels em nível de cinza: determina se a imagem é mais clara ou mais escura por meio de análises de pixels individuais.

\footnotetext{
${ }^{1}$ Base de imagens disponível em http://fei.edu.br/ cet/facedatabase.html
} 
- Média dos pixels em RGB: determina se a imagem é mais clara ou mais escura por meio de análises de pixels individuais, considerando cada canal de cor separadamente.

- Desvio padrão dos pixels em nível de cinza: determina o índice de variação de cores da imagem por meio de análises de pixels individuais.

- Desvio padrão dos pixels em RGB: determina o índice de variação de cores da imagem por meio de análises de pixels individuais, considerando cada canal de cor separadamente.

- Obliquidade dos pixels em nível de cinza: determina a variação de cores da imagem por meio de análises de pixels individuais.

- Obliquidade dos pixels em RGB: determina a variação de cores da imagem por meio de análises de pixels individuais, considerando cada canal de cor separadamente.

Os extratores de textura são:

- Contraste: determina a relação de cores observada entre objeto e fundo da imagem.

- Entropia: determina um valor que representa a dispersão dos pixels na imagem.

Os extratores de forma são:

- Escala: compara o tamanho dos rostos em duas imagens, utilizando índice de escala.

- Rotação: determina os eixos de inércia de duas imagens e os compara.

- Translação: analisa os rostos das imagens, de modo a definir orientações e prolongamentos em suas formas.

Os extratores apresentados consistem em algoritmos que, após executarem cálculos com a imagem no domínio espacial, retornam um número, o qual representa o valor de característica para uma determinada imagem. Posteriormente, este valor é normalizado no intervalo entre zero e um. O conjunto de valores resultantes de extratores aplicados em uma imagem formam o seu vetor de características, o qual é usado como argumento de uma função de distância para comparar a semelhança da imagem em questão com a imagem modelo.

O escopo do presente trabalho não inclui a discussão da relevância dos extratores apresentados. No entanto, uma das preocupações é que o usuário possa visualizar a relevância de cada extrator e sua influência na composição da mensuração de distância total. Assim, foi proposta e implementada uma barra de extratores que permite avaliar o quanto cada extrator contribui para o valor total de distância, em valores absolutos e porcentagens, conforme descrito na seção 3.3 .

\subsection{Similaridade entre as imagens}

As técnicas de visualização propostas expressam a similaridade entre as imagens por meio do tamanho e/ou do posicionamento de cada uma delas. As imagens mais semelhantes à imagem modelo têm tamanhos maiores e/ou estão mais próximas do ponto de vista do usuário. Em contrapartida, as imagens menos semelhantes à imagem modelo têm tamanhos menores e/ou estão mais distantes do ponto de vista do usuário. 
Salienta-se que os extratores anteriormente apresentados são algoritmos de processamento de imagens que extraem características das imagens, a fim de verificar o quanto duas imagens são similares semanticamente. $\mathrm{O}$ tamanho e o posicionamento não são fatores considerados para medir a similaridade, mas são expressões da similaridade entre as imagens, mensurada por uma função de distância. Isso significa que essas duas propriedades de visualização (tamanho e posicionamento) são usadas para indicar o quanto uma imagem é similar à outra, considerando o valor obtido pela função de distância.

A fim de evitar que a imagem modelo e as imagens mais semelhantes assumissem tamanhos muito grandes e que as imagens menos semelhantes assumissem tamanhos muito pequenos, foram definidos, empiricamente, tamanhos (largura $\mathrm{x}$ altura) máximos e mínimos de imagem em pixels - 160 x 140 e 2 x 2, respectivamente. Estes tamanhos foram definidos de modo a garantir que a interface do sistema pudesse exibir uma quantidade de imagens suficiente para que o usuário estabelecesse comparações.

A semelhança entre as imagens é definida pela distância euclidiana entre uma imagem de uma base de imagens e a imagem modelo selecionada. Cada imagem da base é processada e são obtidos os valores dos dezessete extratores para cada imagem. Com esses valores, é criada uma matriz que disponibiliza o valor calculado para cada extrator. Os valores dos extratores utilizados são normalizados. Na sequência, a distância euclidiana entre cada uma das imagens da base e a imagem modelo é calculada e armazenada em um vetor de distâncias, que também são normalizadas.

Seja $m$ uma imagem modelo, $e_{n m}$ o valor do extrator $n$ da imagem $m, i$ uma segunda imagem e $e_{n i}$ o valor do extrator $n$ da imagem $i . D_{m, i}$ é a distância euclidiana entre as imagens $m$ e $i$, dada pela equação 1 .

$$
D_{m, i}=\sqrt{\sum_{n=1}^{17}\left(e_{n m}-e_{n i}\right)^{2}}
$$

A partir dos valores das distâncias, os tamanhos de cada imagem são definidos. Como essas distâncias foram normalizadas, foi possível utilizá-las como fator multiplicador do tamanho e da largura máximos. Entretanto, como o tamanho da imagem é inversamente proporcional à sua distância euclidiana, as distâncias foram usadas de modo invertido. $\mathrm{O}$ fator multiplicador da i-ésima imagem mais semelhante é, na verdade, a distância euclidiana da i-ésima imagem menos semelhante e vice-versa. Em outras palavras, o tamanho da imagem modelo, por exemplo, é o máximo, pois seu fator multiplicador é 1. Esse é o maior valor do vetor de distâncias normalizado e corresponde à imagem menos semelhante. Entretanto, a imagem menos semelhante tem tamanho mínimo, pois seu fator multiplicador é zero, ou seja, o menor valor de distância. Para evitar que as imagens menos semelhantes tenham tamanho nulo, é utilizado o maior valor entre o produto do tamanho máximo pelo fator de distância e o tamanho mínimo mencionado anteriormente.

As equações 3 e 4 definem o cálculo dos tamanhos das imagens, dada a distância euclidiana $D_{m, x_{i}}$ entre a imagem modelo $m$ e a imagem $x_{i}$, determinada pela equação 2 .

$$
x_{i}=(\text { total de imagens })-(i-1)
$$




$$
\begin{aligned}
\text { altura }_{i} & =\max \left(160 * D_{m, x_{i}}, 2\right) \\
\text { largura }_{i} & =\max \left(140 * D_{m, x_{i}}, 2\right)
\end{aligned}
$$

Além dos tamanhos proporcionais à similaridade, também foram disponibilizadas visualizações dos valores dos extratores. A cada imagem é associada uma barra vertical que mostra, por meio de cores, o quanto cada extrator contribuiu para o valor de distância obtido (seção 3.3). Cada cor representa um dos dezessete extratores utilizados pelo sistema. Quanto maior a predominância da cor, maior a contribuição do extrator por ela representado no valor final da distância da imagem.

Adicionalmente, o sistema permite ao usuário escolher as imagens de um diretório para criar uma base de imagens. Cada uma das imagens é processada e são criados, então, uma matriz de extratores (imagem versus extrator) e um vetor de distâncias, como explicado anteriormente. Após o processamento das mesmas, o usuário pode gravar a base em um arquivo texto e dispensar a necessidade de reprocessar as imagens a cada execução. Também é possível alterar a imagem modelo e reexibir a base de imagens de acordo com os valores dos extratores da nova imagem modelo, sem recalcular os valores dos extratores de cada imagem.

\subsection{Exibição dos detalhes da imagem}

A fim de complementar as técnicas de visualização propostas, uma funcionalidade adicional foi definida para exibir os detalhes da imagem. Esta funcionalidade agrega todas as informações disponíveis sobre uma determinada imagem: a distância em relação à imagem modelo, a sua barra de extratores, os valores absolutos e percentuais de cada extrator, além da legenda de cores (Figura 1). Nas visualizações tridimensionais, esta interface é acessível pelo menu "Detalhes". Nas visualizações bidimensionais, também é possível acessá-la selecionando uma das imagens.

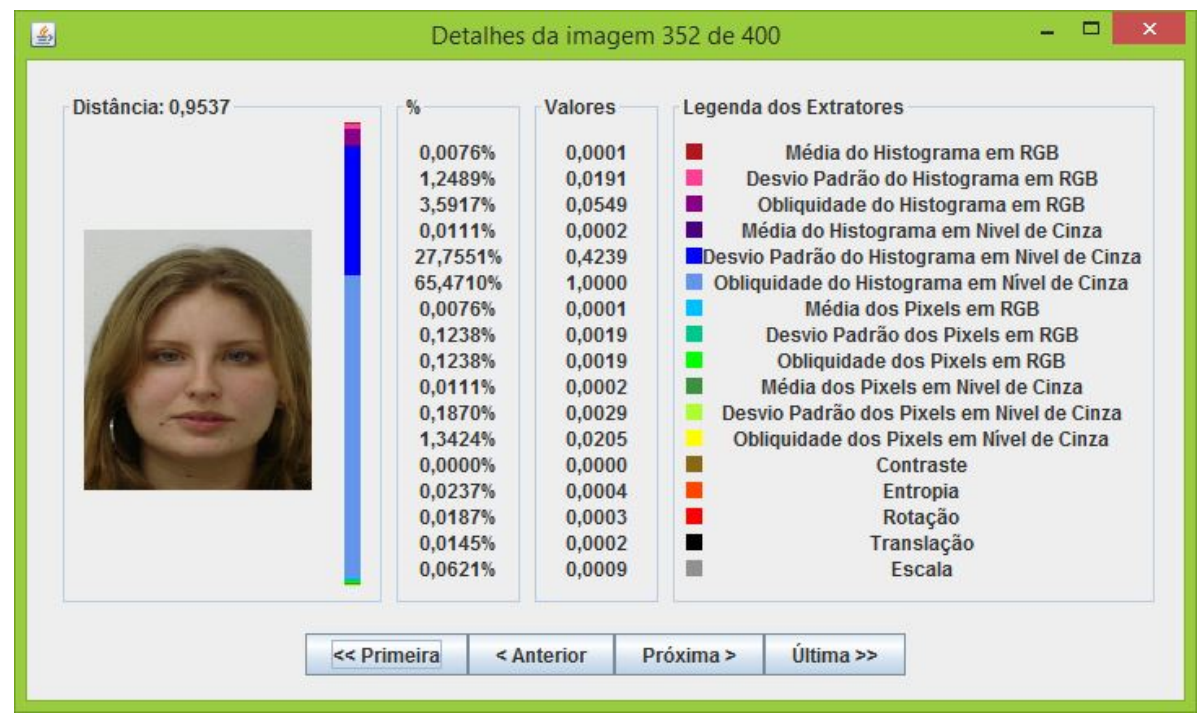

Figura 1. Tela de visualização dos detalhes de uma imagem.

No topo da interface, o valor da distância da imagem é exibido. Em seguida são exibidas as imagens e suas barras de extratores. Ao lado, são exibidos os valores 
percentuais em relação à distância. É a partir das porcentagens que a predominância das cores é definida na barra de extratores. Também são exibidos os valores absolutos normalizados de cada extrator, que foram utilizados para calcular a distância.

Esta abordagem, diferentemente das encontradas na literatura pesquisada, explicita o processo de classificação das imagens. As barras facilitam o entendimento do usuário sobre a razão de uma imagem ser mais semelhante ou menos semelhante à imagem modelo.

\subsection{Visualização bidimensional linear}

A técnica de visualização bidimensional linear visa a apresentar as imagens recuperadas em uma fila no domínio bidimensional, de forma que as primeiras são aquelas mais semelhantes à imagem modelo. Baseada no trabalho de [Pinto-Cáceres 2010], as imagens são exibidas em tamanhos diferentes a fim de ressaltar o quão semelhantes são em relação à imagem modelo. $\mathrm{O}$ tamanho de cada imagem é proporcional à distância euclidiana entre ela e a imagem modelo. A interface resultante da implementação dessa técnica pode ser observada na Figura 2.

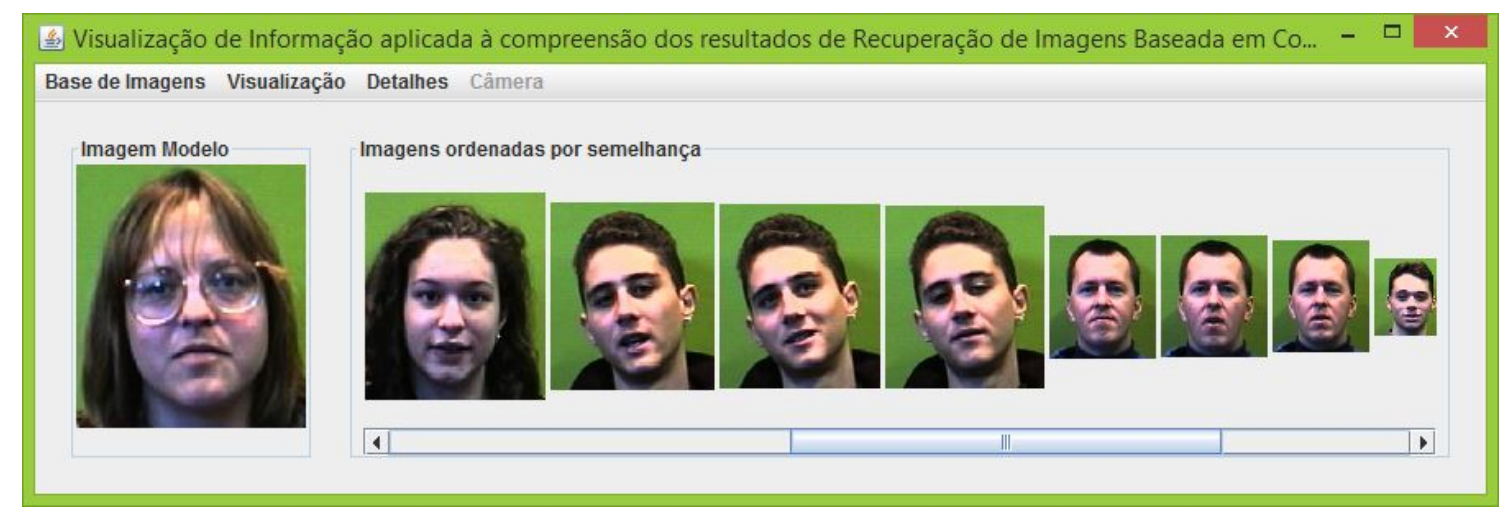

Figura 2. Visualização bidimensional linear.

Esta técnica possibilita ao usuário identificar visualmente grupos de imagens de acordo com a relevância, que é dada pelos tamanhos das próprias imagens. É possível navegar por toda a base de imagens sem perder a referência da imagem modelo, que permanece sempre visível.

\subsection{Visualização bidimensional em espiral}

$\mathrm{Na}$ técnica de visualização bidimensional em espiral, é exibida uma espiral concêntrica tendo a imagem modelo localizada no seu centro. As imagens retornadas na busca são posicionadas em relação ao centro da espiral considerando a semelhança existente entre cada imagem e a imagem fornecida como consulta.

Para esta técnica de visualização foram definidas duas abordagens. Na primeira abordagem - Figura 3(a) - a distância relativa à imagem modelo é utilizada para definir o tamanho de cada uma das imagens. Na segunda abordagem - Figura 3(b) - há um aumento na distância entre cada volta da espiral, sendo que o tamanho das imagens se mantém constante. 


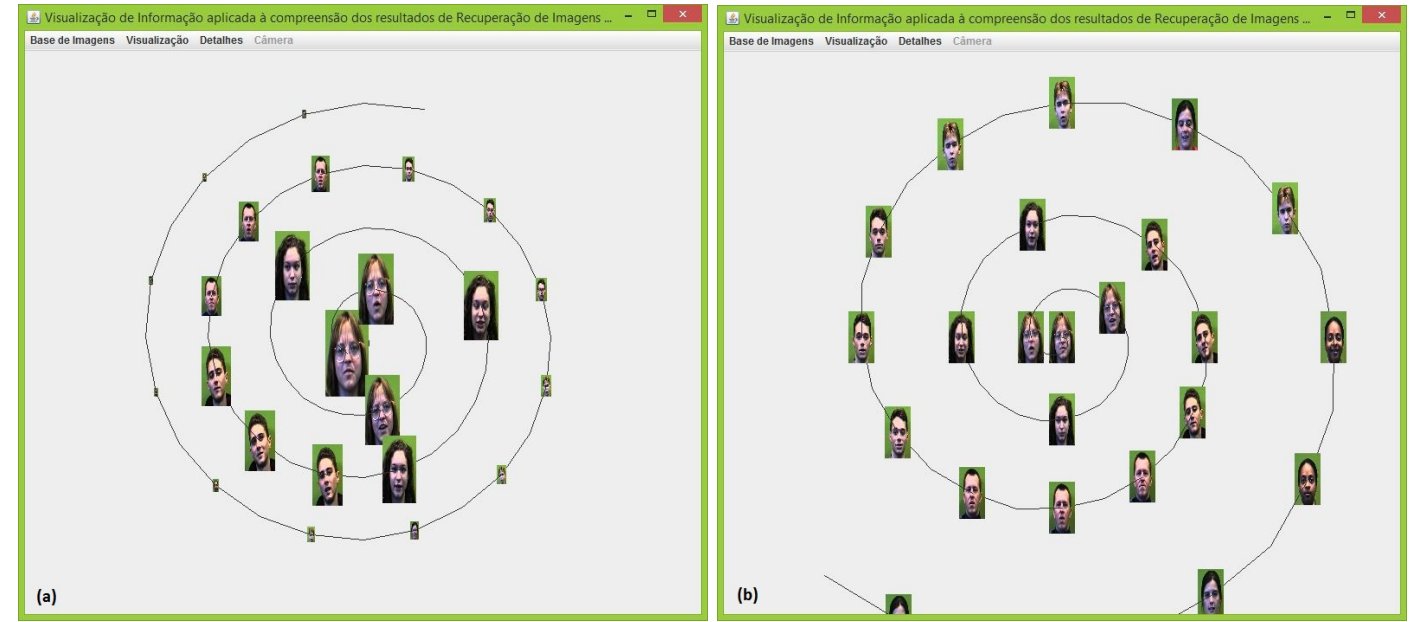

Figura 3. Visualização bidimensional em espiral: (a) primeira abordagem com tamanhos proporcionais à distância relativa à imagem modelo; (b) segunda abordagem: tamanho único de imagem, com aumento da distância entre as voltas da espiral.

Diferentemente da visualização bidimensional linear, a disposição em espiral fornece uma visão geral de todas as imagens, facilitando a comparação entre elas. Todavia, quando a base de dados contém uma quantidade muito grande de imagens, pode não ser possível visualizar todos os componentes de forma nítida e a distribuição das mesmas, na espiral, torna-se radial.

As imagens foram redimensionadas e posicionadas em uma espiral, utilizando o Algoritmo 1] [Lyon 2001]. Em linhas gerais, esse algoritmo calcula as coordenadas $(x, y)$ dos pontos que formam uma espiral de Arquimedes. Os parâmetros da espiral são incrementados a cada iteração do laço, enquanto houver imagens para exibir e posicionar na interface do sistema. A variável $k$, utilizada como entrada pelo algoritmo, representa o valor que define a distância entre voltas sucessivas da espiral [Santos 2007]. Definiuse, empiricamente, o valor de $k$ como 0,2 . Na primeira abordagem, este valor se mantém constante. Na segunda, ele é incrementado em $2 \%$ a cada iteração. Dessa maneira, quanto maior for a distância relativa à imagem modelo, maior será a distância entre as voltas da espiral.

\subsection{Visualização tridimensional linear}

A visualização tridimensional linear é a primeira proposta que visa a apresentar os resultados do sistema de CBIR em um ambiente tridimensional. Consiste em uma adaptação da visualização bidimensional linear para o domínio 3D. Devido ao novo paradigma, as imagens agora são projetadas como texturas em cubos 3D, visando a permitir sua visualização a partir de diversos ângulos, uma vez que é permitido ao usuário executar operações de rotação, translação e aproximação (zoom) no ambiente virtual tridimensional.

Assim como na visualização anterior, foram definidas duas abordagens distintas. Na primeira abordagem, as imagens são distribuídas em filas de quatro cubos e o tamanho de cada um dos cubos é proporcional à distância entre a imagem usada como textura e a imagem modelo. Na segunda abordagem, todos os cubos possuem o mesmo tamanho, 


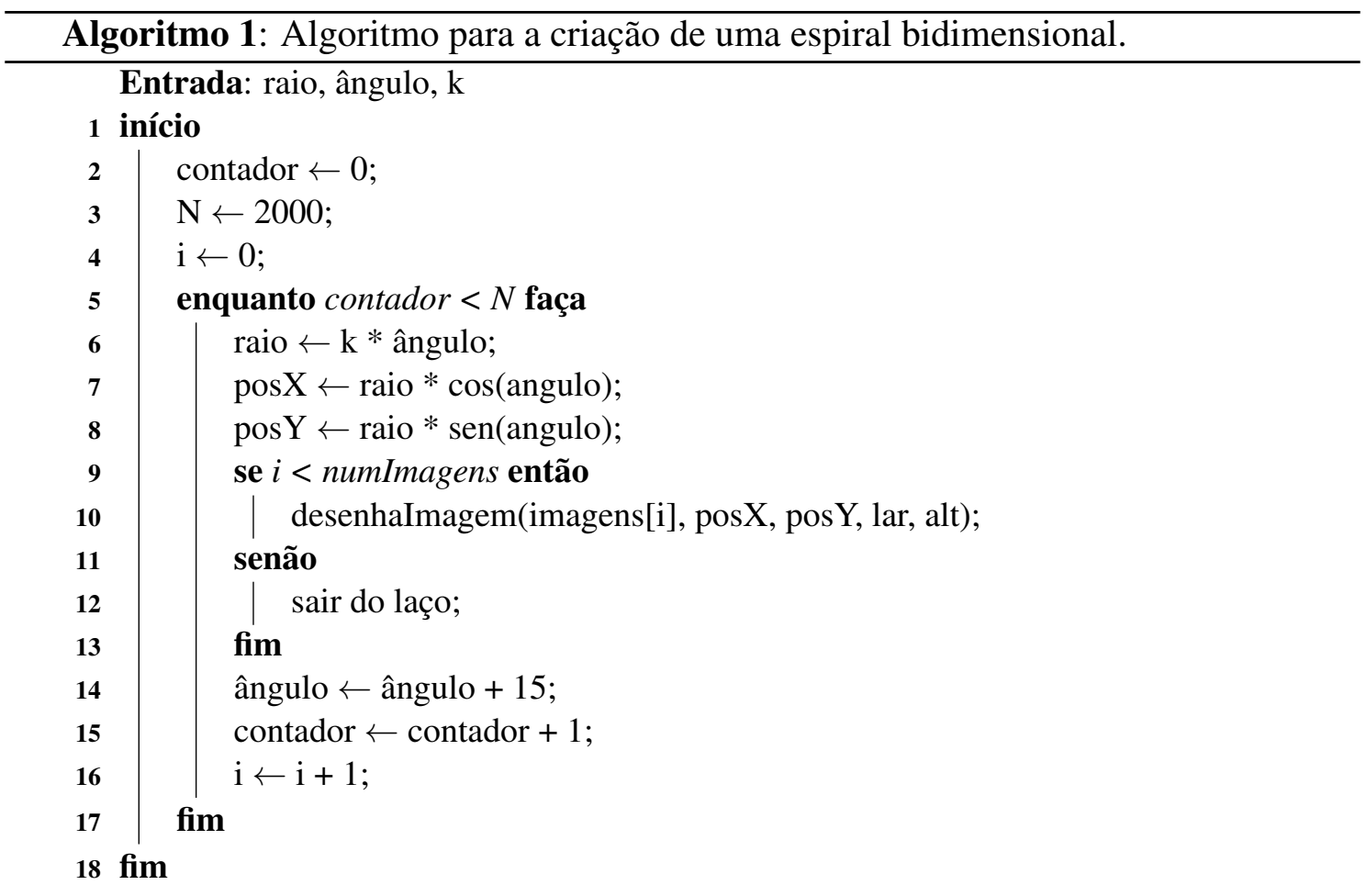

entretanto estes são enfileirados de modo que as imagens mais semelhantes estejam mais próximas do ponto de vista do usuário.

Conforme pode ser conferido na Figura 4(a), filas tridimensionais são formadas por cubos, cujas texturas são as imagens da base em uso. Cada fila é composta por até quatro cubos. A Figura 4(b) mostra a segunda abordagem, na qual os cubos têm o mesmo tamanho e formam uma única fila. Deste modo, imagens mais semelhantes aparecem mais próximas ao ponto de vista do usuário e imagens menos semelhantes aparecem mais distantes.
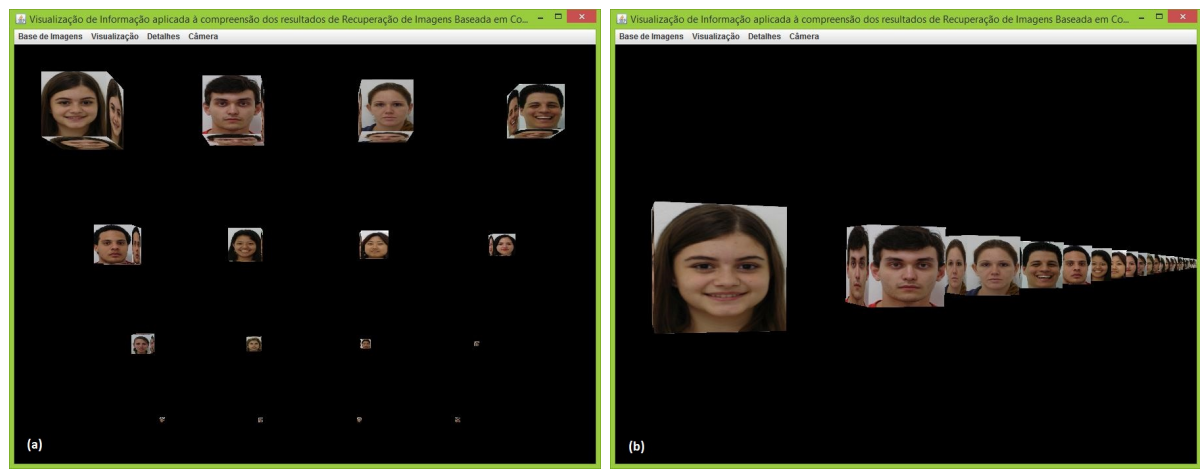

Figura 4. Visualização tridimensional linear: (a) primeira abordagem com múltiplas filas; (b) segunda abordagem com uma única fila.

Em ambas as abordagens, a navegação no ambiente tridimensional é realizada por meio de três ações: rotação, translação e zoom (aproximar/afastar) (Figura 5).

Para criar esta visualização, o Algoritmo 2 foi implementado. Cada uma das fi- 

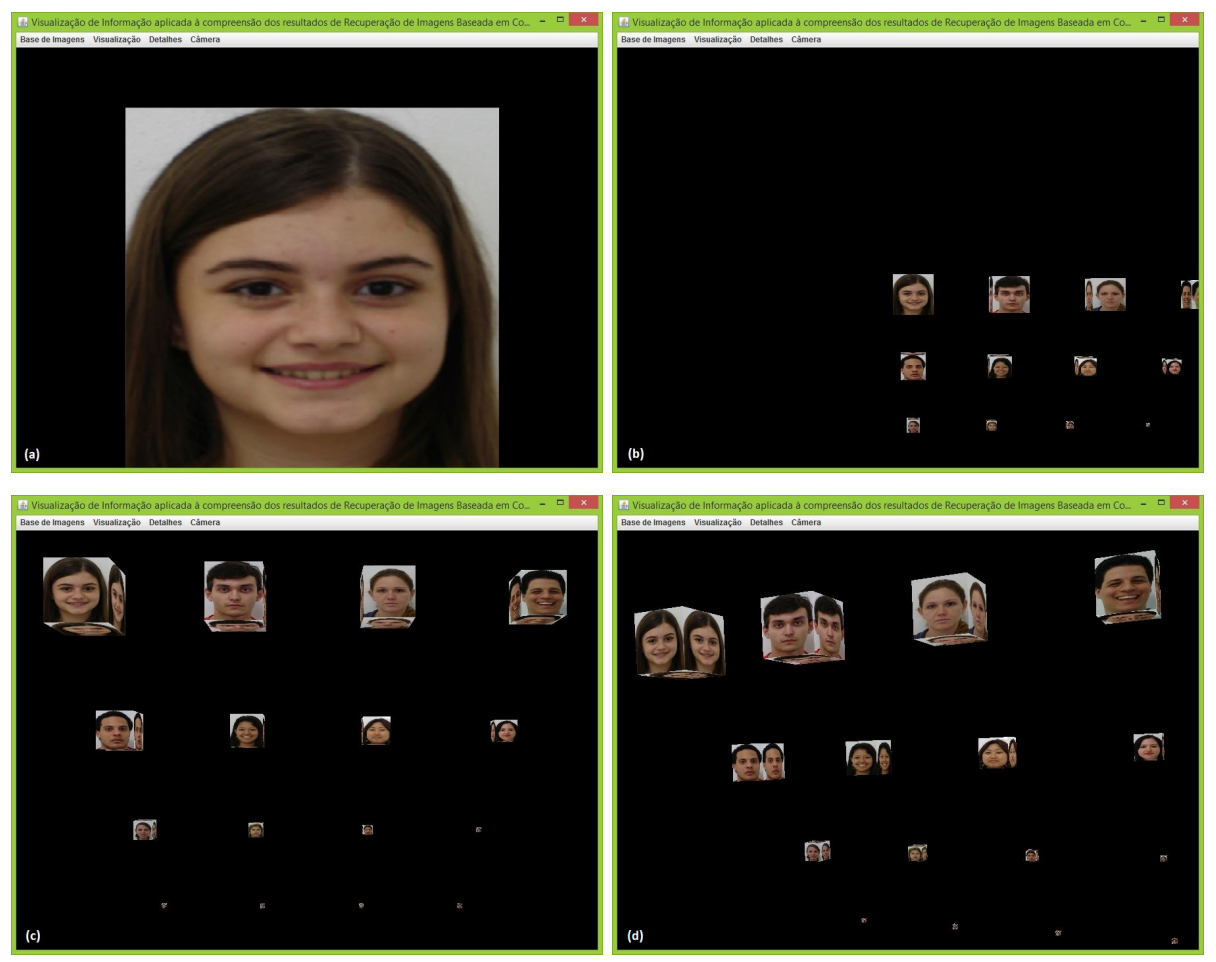

Figura 5. Visualização tridimensional linear: (a) estado inicial; (b) aplicação de zoom out; (c) translação da cena; (d) rotação da cena.

leiras de cubos exibe quatro imagens. Por essa razão, a quantidade de fileiras é definida como a soma do resultado da divisão do número de imagens por 4 e o resto da mesma divisão. Para criar e exibir os cubos, os dois laços encadeados garantem que, a cada iteração do laço interno, as variáveis de controle e outras se apliquem a apenas uma fileira por vez. Dessa forma, é possível utilizar a variável aresta de forma que ela armazene o tamanho do último cubo de uma fileira. Consequentemente, o primeiro cubo da fileira seguinte terá um tamanho menor do que o último cubo da fileira anterior.

Assim como na visualização em linha com detalhes, a posição e o tamanho dos cubos determinam a similaridade entre as imagens. Quanto mais acima, à esquerda e maior o cubo, maior a similaridade entre a imagem em questão e a imagem modelo. Para a segunda abordagem, as imagens são posicionadas lado a lado (eixo $x$ ), na mesma altura (eixo y) e uma atrás da outra (valores negativos no eixo $z$ ). Em ambos os casos, é possível obter uma visão geral das imagens, o que pode facilitar o entendimento do resultado apresentado.

\subsection{Visualização tridimensional em espiral}

A visualização tridimensional em espiral é a segunda técnica de exibição dos resultados de sistemas CBIR em ambientes tridimensionais. Consiste em uma adaptação da visualização 2D em espiral para o domínio 3D. Assim como na primeira técnica no domínio 3D (seção 3.6), as imagens são projetadas como texturas em cubos 3D, visando a permitir sua percepção a partir de diversos ângulos.

Esta visualização não redimensiona as imagens. Cada cubo tem sua posição definida por três coordenadas $(x, y, z)$. Assim, a profundidade e a altura dos cubos no espaço 


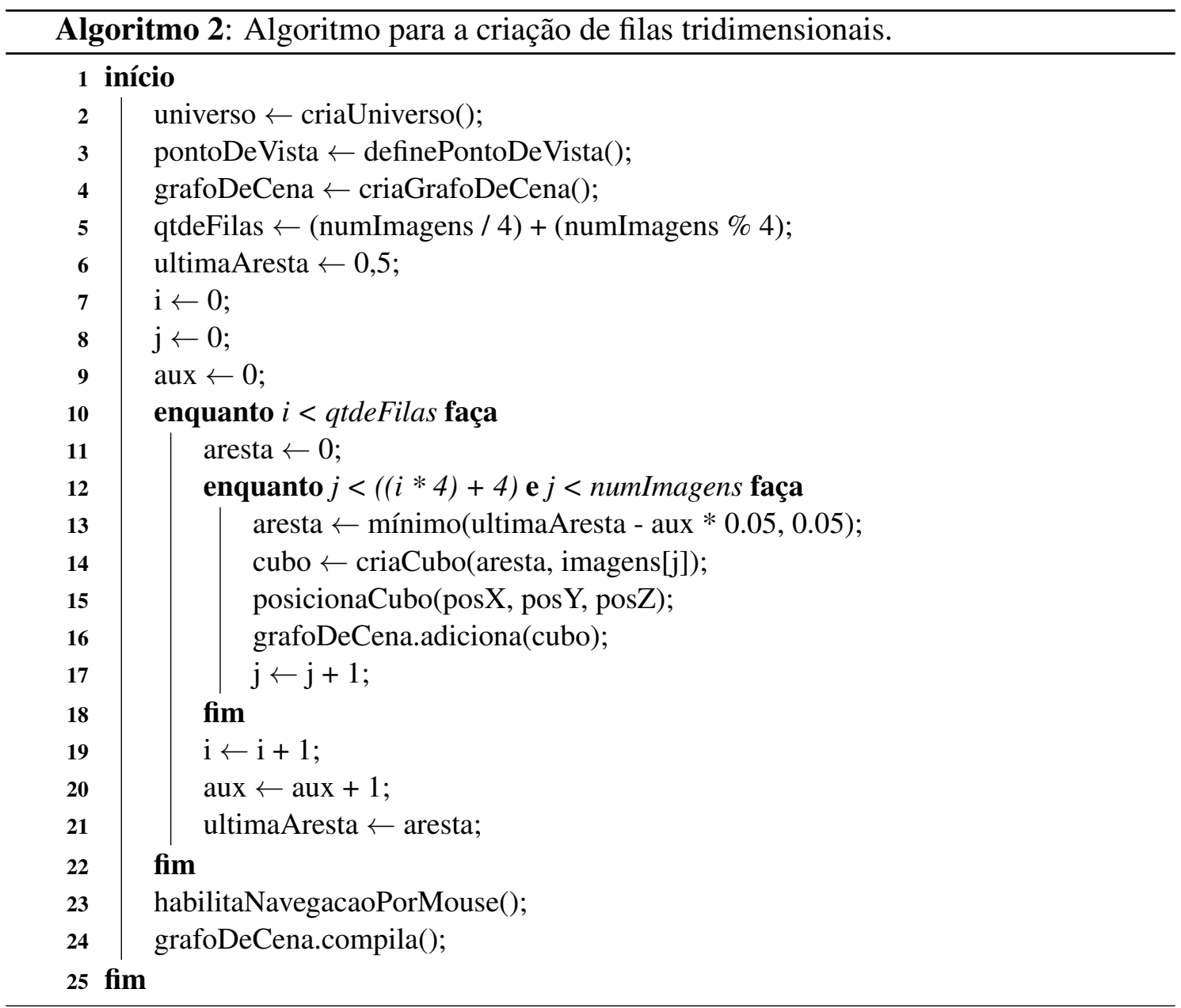

determina o tamanho dos mesmos, quando observados do ponto de vista inicial (Figura 6).
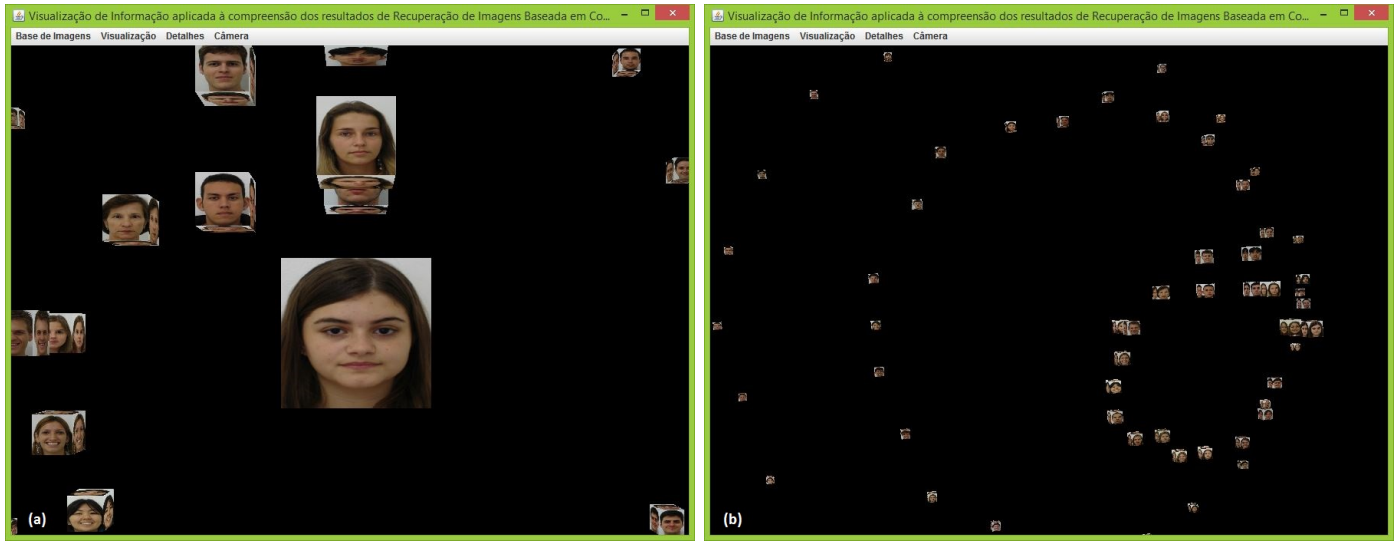

Figura 6. Visualização tridimensional em espiral.

Os cubos estão dispostos em uma espiral. Quanto mais próxima a imagem estiver do ponto de vista inicial, mais semelhante à imagem modelo ela será. A navegação é idêntica à da visualização tridimensional linear.

O Algoritmo 1 é empregado para gerar essa visualização, calculando as coordena- 
das $(x, y)$. São criados cubos (utilizando as imagens da base como texturas) os quais são posicionados no espaço tridimensional de acordo com as coordenadas $(x, y)$ calculadas. A profundidade de cada cubo, ou seja, a coordenada $z$, é sempre única e negativa. São estas duas restrições que garantem que os cubos se afastem de acordo com a similaridade com a imagem modelo e formem uma espiral tridimensional.

\subsection{Visualização tridimensional em cone}

A visualização tridimensional em cone é a terceira técnica de visualização implementada no domínio 3D. Assim como nas técnicas anteriores para o domínio 3D, as imagens da base são utilizadas como texturas de cubos. Os cubos são organizados em círculos concêntricos. Cada círculo ocupa uma posição única e negativa no eixo $z$ de maneira a determinar o tamanho de cada um deles quando observados do ponto de vista inicial (Figura 7).
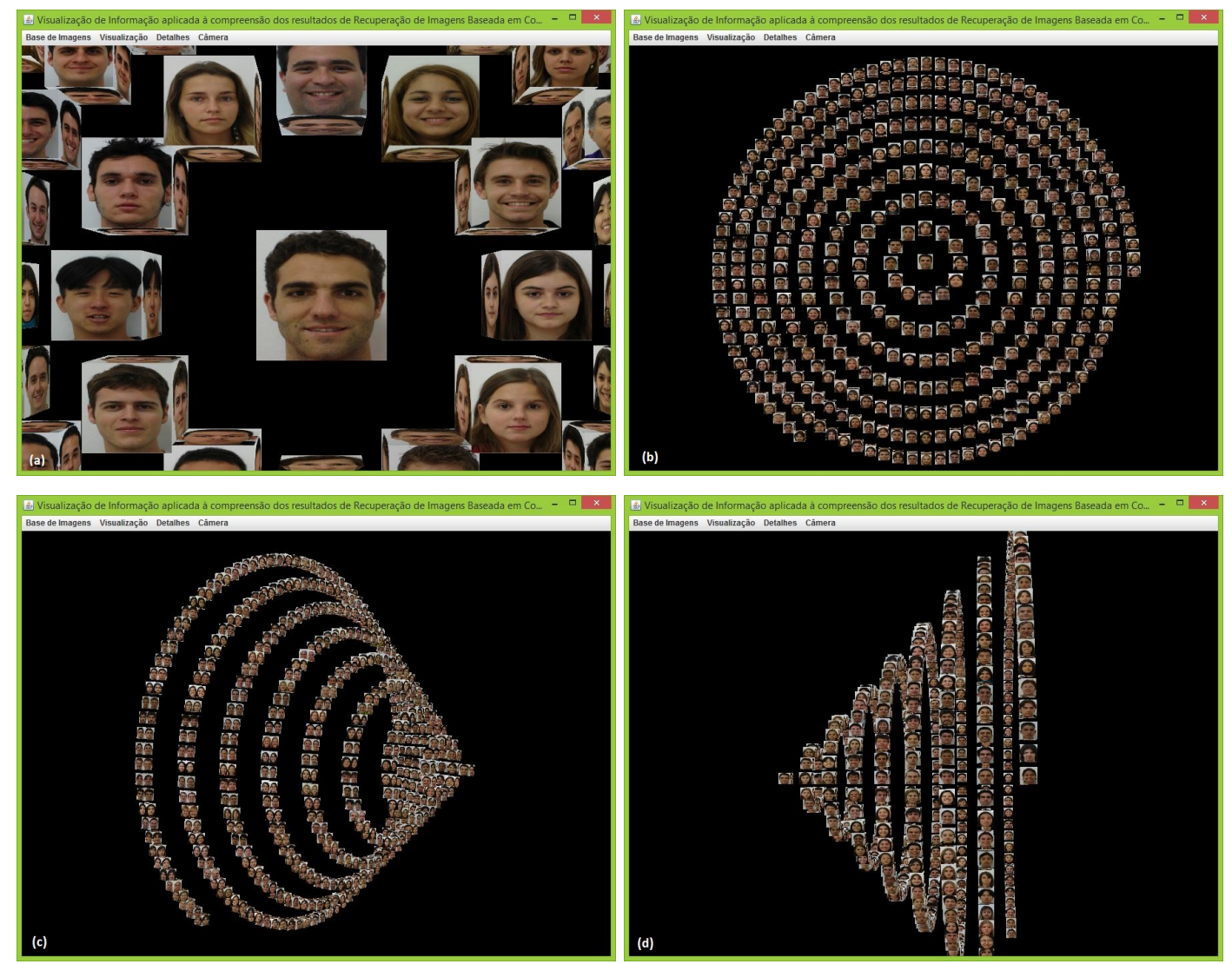

Figura 7. Visualização tridimensional em cone: (a) posição inicial; (b) aplicação de zoom out; (c)(d) visão após rotação e translação.

A posição dos cubos em cada círculo é dada pela distância relativa à imagem modelo, que por sua vez está posicionada na ponta do cone. Tomando como base as coordenadas de um círculo no plano cartesiano $(x, y)$, as imagens estão ordenadas no sentido anti-horário, a partir da posição $(x, 0)$, em que $x$ é o raio do círculo. Na Figura 7(a), a imagem mais semelhante está posicionada à direita da imagem modelo, na posição $(1,0)$.

O Algoritmo 3 foi implementado a fim de definir as coordenadas $(x, y)$ de cada 
cubo de maneira a formar círculos concêntricos com a aparência de um cone. Em resumo, o algoritmo utiliza múltiplos de 12 (valor empírico) como quantidade ideal de cubos por círculo de modo que haja uma distribuição uniforme dos mesmos. Por consequência, é definido um intervalo (um ângulo) entre cubos. Definido o ângulo em que cada cubo será posicionado, é possível determinar o valor das coordenadas $(x, y)$.

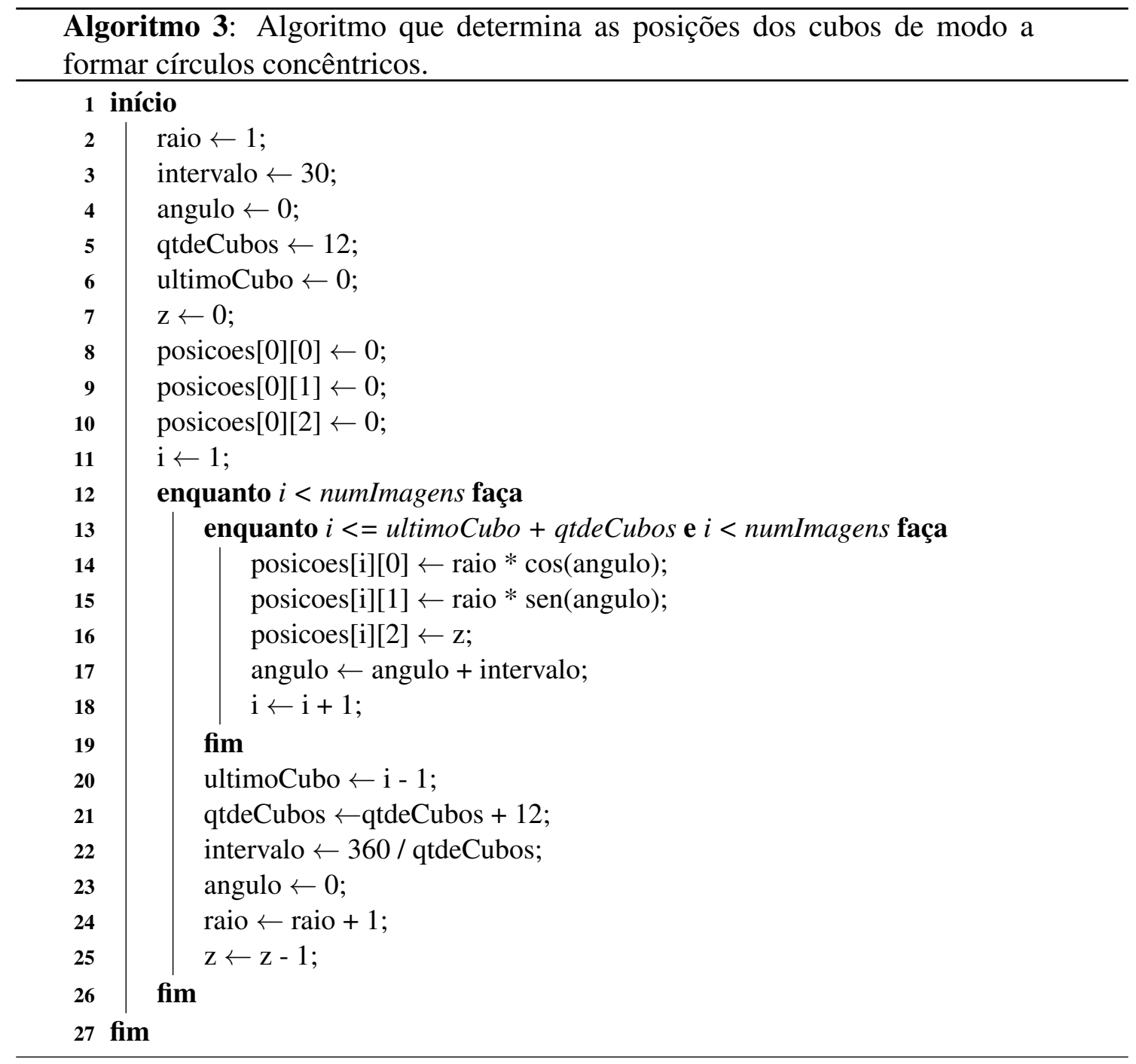

\section{Avaliação das técnicas de visualização propostas}

A fim de avaliar a eficiência e a eficácia das cinco técnicas de VI implementadas e apresentadas, foram elaborados dois testes baseados em tarefas [Pinto-Cáceres 2010]. O primeiro teste envolvia interação com o sistema desenvolvido e teve a participação de 20 voluntários. O segundo teste contou com a participação de 23 voluntários e foi conduzido por meio de questionário disponível na Internet, com a finalidade de aumentar a quantidade de voluntários envolvidos. Ao todo, 43 voluntários participaram dos testes. O objetivo foi verificar se as técnicas, de fato, facilitavam a compreensão dos resultados e determinar qual delas seria considerada mais adequada pelos voluntários. 


\subsection{Avaliação das técnicas via interação do usuário}

O primeiro teste consistiu na execução de tarefas que permitissem ao usuário explorar, interativamente, as características de cada visualização para compreender os resultados do sistema de CBIR. Em vez de solicitar ao usuário a sua apreciação sobre os resultados obtidos em cada tarefa, foram elaboradas questões cujas respostas permitem inferir o quanto as técnicas de visualização avaliadas contribuíram para a compreensão dos resultados.

Após uma explicação inicial ao usuário, este foi solicitado a executar o seguinte roteiro para cada uma das técnicas disponibilizadas:

1. Identifique a imagem modelo.

2. Qual é a quinta imagem mais semelhante à imagem modelo?

As tarefas foram cronometradas, a fim de estabelecer comparativos entre as técnicas propostas. A Tabela 2 indica a porcentagem de voluntários que completaram as tarefas com sucesso, além do tempo médio utilizado para executá-las.

Tabela 2. Resultados da avaliação das cinco técnicas de visualização com interação dos voluntários.

\begin{tabular}{|l|c|c|c|c|}
\hline \multirow{2}{*}{\multicolumn{1}{c|}{ Técnica }} & \multicolumn{2}{c|}{ Imagem modelo } & \multicolumn{2}{c|}{$\mathbf{5}^{\mathbf{a}}$ imagem mais semelhante } \\
\cline { 2 - 5 } & Taxa de acerto & Tempo médio & Taxa de acerto & Tempo médio \\
\hline 2D Linear & $100 \%$ & $1 \mathrm{~s}$ & $100 \%$ & $5,5 \mathrm{~s}$ \\
\hline 2D Espiral & $100 \%$ & $1 \mathrm{~s}$ & $100 \%$ & $8 \mathrm{~s}$ \\
\hline 2D Espiral (versão 2) & $100 \%$ & $1 \mathrm{~s}$ & $100 \%$ & $5,5 \mathrm{~s}$ \\
\hline 3D Linear & $100 \%$ & $1 \mathrm{~s}$ & $100 \%$ & $11 \mathrm{~s}$ \\
\hline 3D Linear (versão 2) & $100 \%$ & $1 \mathrm{~s}$ & $100 \%$ & $6,5 \mathrm{~s}$ \\
\hline 3D Espiral & $100 \%$ & $1 \mathrm{~s}$ & $100 \%$ & $26,5 \mathrm{~s}$ \\
\hline 3D Cone & $100 \%$ & $1 \mathrm{~s}$ & $100 \%$ & $13,5 \mathrm{~s}$ \\
\hline
\end{tabular}

Todos os usuários identificaram corretamente a imagem modelo e a quinta imagem mais semelhante. É possível observar que as visualizações bidimensionais possibilitaram aos usuários cumprir as tarefas em tempos menores.

A visualização bidimensional em espiral mostrou-se menos eficiente do que a linear. Inicialmente, uma pequena parte dos voluntários teve dificuldade para entender a dinâmica da espiral. Em contrapartida, nenhum deles teve dificuldades em localizar a imagem modelo. Entretanto, a abordagem alternativa da visualização bidimensional em espiral mostrou-se tão eficiente quanto a bidimensional linear. Já familiarizados com a espiral, os usuários não tiveram dificuldades em entender a organização das imagens. Todos indicaram que o espaçamento entre as voltas da espiral facilitava a execução da tarefa solicitada.

$\mathrm{Na}$ avaliação da visualização tridimensional linear, todos os usuários precisaram de um tempo maior do que o observado nas técnicas bidimensionais para encontrar a quinta imagem mais semelhante à imagem modelo. Este fato pode ser explicado pela ordem em que as técnicas foram apresentadas aos usuários. Esta foi a primeira técnica tridimensional avaliada e, por essa razão, houve dificuldades iniciais de navegação no ambiente tridimensional. A segunda abordagem da visualização tridimensional linear mostrou-se mais eficiente. Os cubos possuem o mesmo tamanho e são posicionados em 
uma única fila, simplificando o entendimento e a navegação. Todos os usuários tiveram mais facilidade, em comparação à primeira abordagem, em desempenhar as tarefas solicitadas.

Ao utilizar a visualização tridimensional em espiral, os voluntários cumpriram a tarefa 2, em média, em 26,5 segundos. Esta visualização teve o pior desempenho entre todas. Apesar de já conhecerem os conceitos de extrator, de similaridade e o sistema em geral, os usuários enfrentaram uma dificuldade muito grande em navegar no ambiente tridimensional e em compreender a espiral. Contrariando as expectativas iniciais, a espiral tridimensional não facilitou, na medida esperada, a compreensão do resultado apresentado. A principal sugestão dos voluntários foi desenhar uma linha ligando os cubos a fim de evidenciar a espiral.

A visualização tridimensional em cone corrigiu o principal problema da espiral tridimensional ao ser mais facilmente compreendida, porém exigiu uma explicação sobre a organização das imagens nos círculos concêntricos. Faltou incluir elementos que indicassem a ordem em que as imagens estão dispostas. Muitos usuários sugeriram, novamente, a utilização de uma linha que ligasse cada um dos cubos.

A Figura 8 apresenta um comparativo entre as técnicas de visualização propostas quanto ao tempo médio utilizado para encontrar a imagem modelo e a quinta imagem mais semelhante nos testes com interação do usuário.

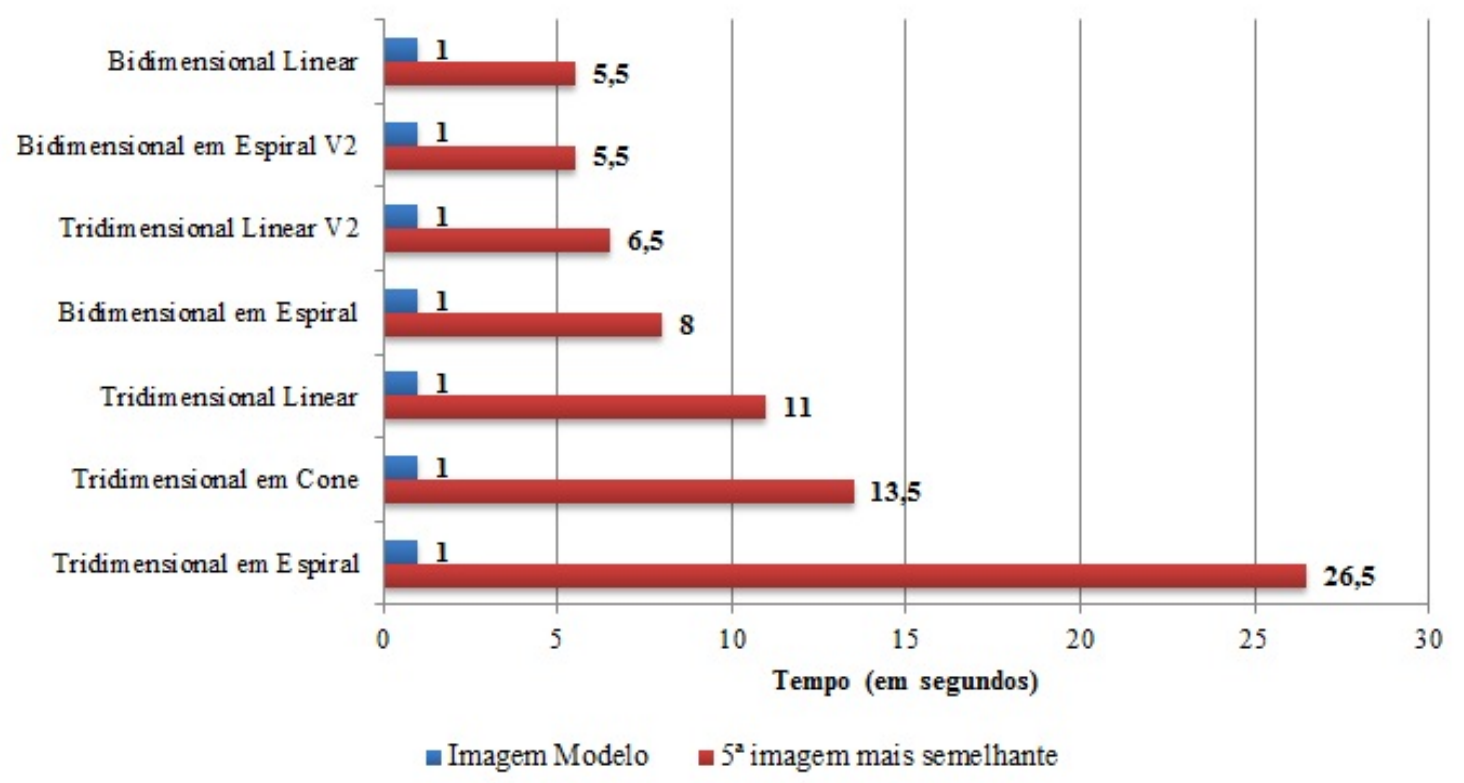

Figura 8. Comparativo entre técnicas de visualização (testes com interação do usuário).

Nota-se que as abordagens adicionais das técnicas bidimensional em espiral e tridimensional linear foram mais eficientes do que as respectivas abordagens originais (espiral com distâncias fixas entre voltas, no caso da técnica 2D em espiral; filas de quatro cubos com tamanhos diferentes, no caso da técnica 3D linear). A segunda abordagem da técnica tridimensional linear obteve o melhor resultado juntamente com a técnica bidimensional linear. A técnica tridimensional em espiral apresentou o pior desempenho e 
a técnica tridimensional em cone mostrou-se mais eficiente do que a espiral. Em todas as formas de visualização, inclusive nas tridimensionais, todos os usuários identificaram imediatamente as imagens modelo.

\subsection{Avaliação das técnicas via questionário}

Para esta avaliação, foi elaborado um questionário onlinę $2^{2}$ o qual foi respondido por 23 voluntários. Após uma explicação inicial, cada usuário foi apresentado às técnicas de visualização e solicitado a executar as seguintes tarefas:

1. Identifique a imagem modelo.

2. Qual é a quinta imagem mais semelhante à imagem modelo?

3. Você tem alguma sugestão de melhoria para essa visualização?

As tarefas 1 e 2 são as mesmas da avaliação com interação com o usuário. Porém, como não houve interação com o sistema, nesta avaliação as mesmas não foram cronometradas. Foram disponibilizadas aos usuários capturas de tela com indicações de letras em algumas das imagens (Figura 9). As respostas às tarefas foram adaptadas em questões de múltipla escolha.

Para evitar que as letras indicassem a resposta das perguntas, as alternativas foram exibidas em ordem aleatória quando as indicações estavam em ordem alfabética e em ordem alfabética quando as indicações estavam em ordem aleatória.

Conforme indica a Tabela 3, 96\% dos usuários conseguiram cumprir as duas tarefas com sucesso utilizando a visualização bidimensional linear. Alguns deles sugeriram que o valor da distância de cada imagem fosse sempre exibido, pois na captura de tela disponibilizada essa informação não foi exibida. Todavia, durante a interação com o sistema, as distâncias podem ser consultadas, a partir de qualquer tela, utilizando o menu "Detalhes"ou por meio de tooltips existentes em cada imagem nas visualizações bidimensionais.

Tabela 3. Resultados da avaliação das cinco técnicas de visualização via questi-
onário online.
\begin{tabular}{|l|c|c|}
\hline \multicolumn{1}{|c}{ Técnica } & Imagem modelo & $\mathbf{5}^{\text {a }}$ imagem mais semelhante \\
\cline { 2 - 3 } & Taxa de acerto & Taxa de acerto \\
\hline 2D Linear & $96 \%$ & $96 \%$ \\
\hline 2D Espiral & $96 \%$ & $96 \%$ \\
\hline 2D Espiral (versão 2) & $91 \%$ & $87 \%$ \\
\hline 3D Linear & $91 \%$ & $82 \%$ \\
\hline 3D Linear (versão 2) & $91 \%$ & $91 \%$ \\
\hline 3D Espiral & $78 \%$ & $61 \%$ \\
\hline 3D Cone & $96 \%$ & $78 \%$ \\
\hline
\end{tabular}

Assim como nos testes com interação, a visualização bidimensional em espiral mostrou-se tão eficiente quanto a bidimensional linear. Porém, no questionário, a abordagem alternativa mostrou-se menos eficiente do que a abordagem original, já que alguns

\begin{tabular}{|c|c|c|c|}
\hline${ }^{2}$ Questionário & disponível & em & https://docs.google.com/forms/d/ \\
\hline
\end{tabular}




\section{Visualização Bidimensional Linear}

Imagem modelo: a imagem escolhida para servir de base para a comparação; aparece sempre em destaque.

Demais imagens: aparecem da mais semelhante a menos semelhante, de acordo com a classificação já feita pelo programa,

utilizando valores numéricos, sem analisar os traços dos rostos.

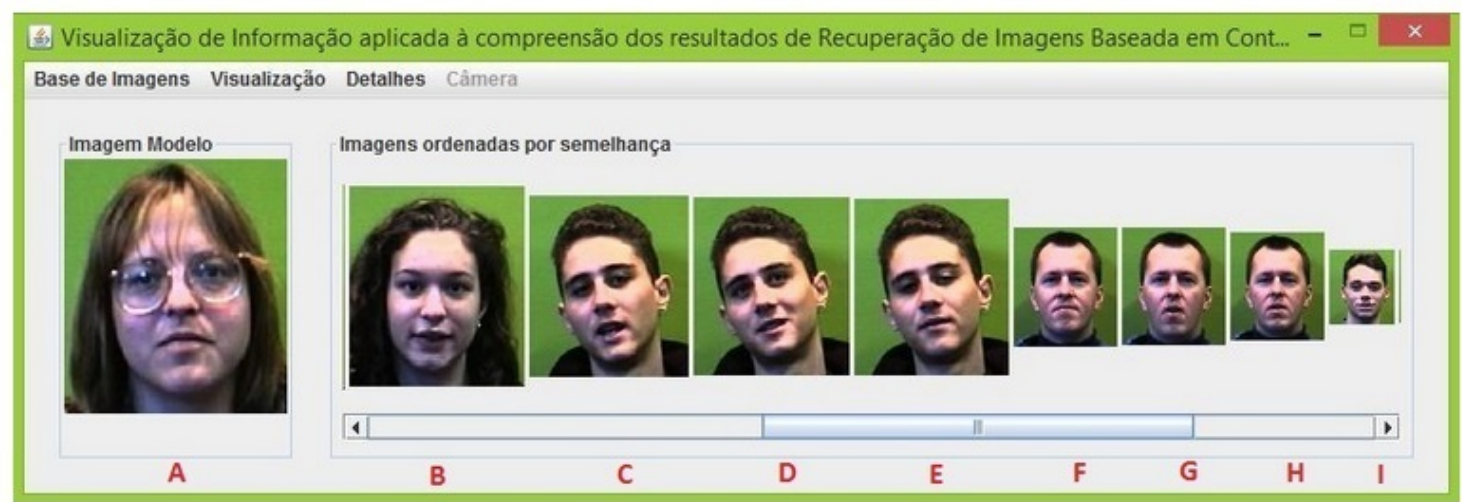

Qual é a imagem modelo?*

Para ampliar a tela, utilize a opção "Abrir imagem em nova guia" de seu navegador

$\mathrm{C}$

A

- G

O $\mathrm{H}$

(-) I

O F

$\mathrm{E}$

- B

D

Figura 9. Primeira tarefa do questionário.

usuários não conseguiram identificar com sucesso a quinta imagem mais semelhante à modelo. Entretanto, nos testes com interação, esta abordagem obteve o melhor resultado. A principal sugestão foi melhorar a disposição e a diminuição do tamanho das imagens.

Novamente, os voluntários tiveram um pouco mais de dificuldade para completar as tarefas utilizando a visualização tridimensional linear. Uma das possíveis razões é que esta foi a primeira técnica tridimensional introduzida no questionário. A segunda abordagem dessa visualização foi mais eficiente em facilitar a compreensão dos resultados e obteve um desempenho melhor do que a primeira abordagem, como ocorreu nos testes com interação.

A visualização tridimensional em espiral não apresentou um desempenho satisfatório: apenas $61 \%$ dos usuários conseguiu identificar a quinta imagem mais semelhante à imagem modelo. A maior parte dos voluntários informou que teve muita dificuldade em entender a espiral.

A visualização tridimensional em cone facilitou a compreensão dos resultados, mas obteve uma taxa de acerto menor do que as visualizações bidimensionais por não ser intuitiva quanto à lógica de organização dos cubos. 
A Figura 10 apresenta um comparativo entre as técnicas avaliadas quanto a taxa de acerto das tarefas propostas aos voluntários.

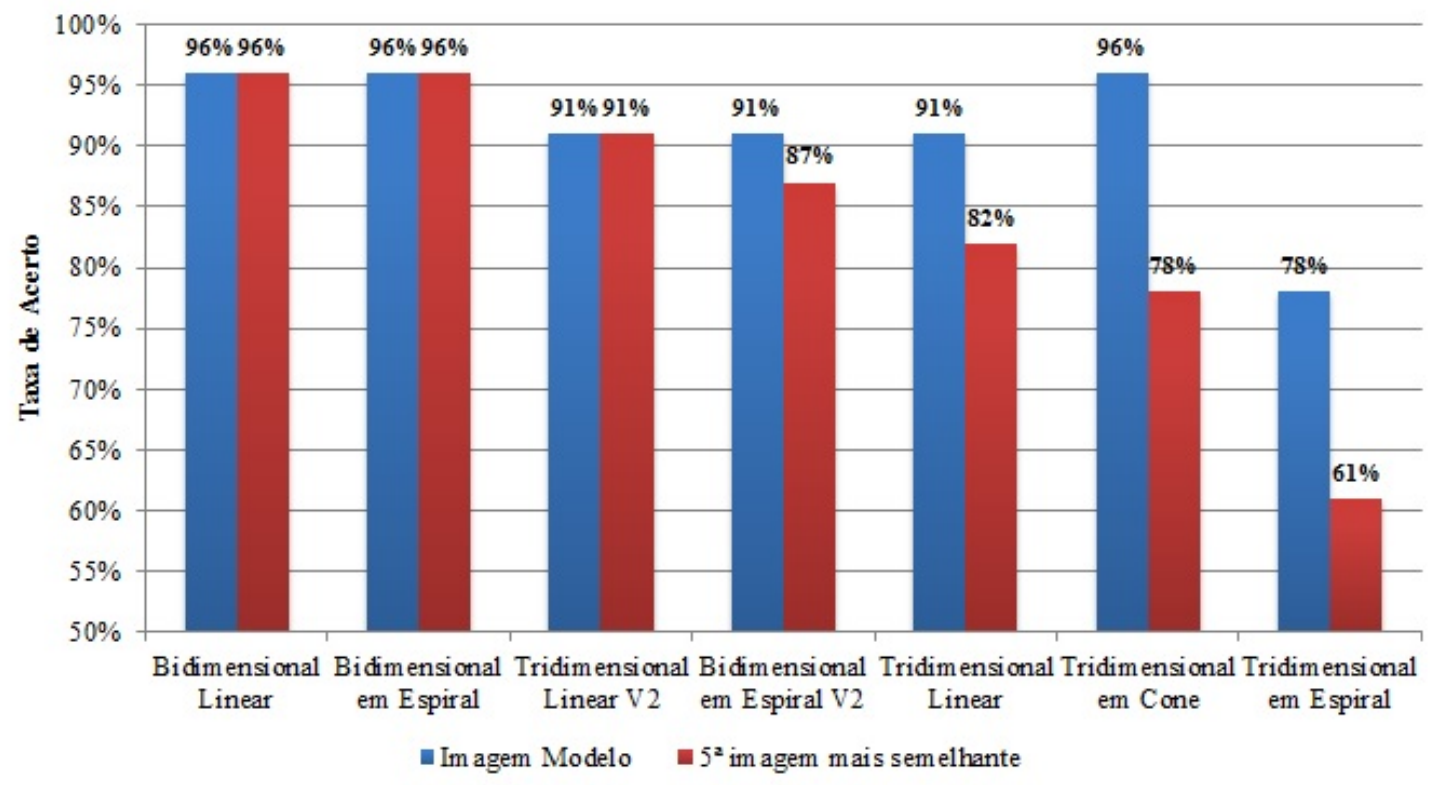

Figura 10. Comparativo entre as taxas de acerto das visualizações nos testes via questionário.

No final do questionário, cada usuário escolheu a sua visualização preferida. $\mathrm{O}$ resultado pode ser visto na Figura 11

\section{Qual visualização mais facilitou a sua compreensão?}

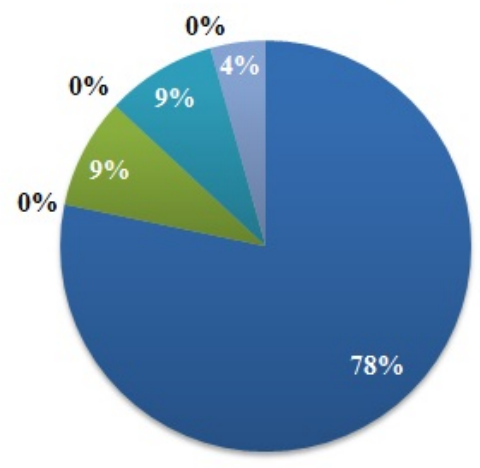

- Bidimensional Linear

- Bidimensional em Espiral

- Bidimensional em Espiral V2

- Tridimensional Linear

- Tridimensional Linear V2

- Tridimensional em Espiral

- Tridimensional em Cone

Figura 11. Gráfico de preferência de visualizações nos testes via questionário.

A visualização bidimensional linear foi a mais citada como melhor técnica tanto entre os usuários que interagiram com o programa quanto entre os que apenas responderam o questionário. Esse fato se deve à simplicidade e à clareza com que as informações são exibidas nessas técnicas. E, corroborando os resultados dos testes, os usuários não consideraram a visualização tridimensional em espiral uma técnica intuitiva. 
As abordagens alternativas das visualizações em espiral e linear (bidimensional e tridimensional), corresponderam às expectativas e facilitaram o entendimento dos resultados quando comparadas às suas respectivas abordagens originais. A visualização em cone mostrou-se eficiente, apesar de exigir maiores explicações sobre a disposição dos cubos.

Apesar de a segunda abordagem da técnica bidimensional em espiral ter sido mais eficiente no teste com interação do que no questionário, é possível afirmar que as técnicas bidimensionais linear e em espiral (segunda abordagem) foram as mais eficientes em facilitar a compreensão dos resultados de CBIR. Nos testes, essas técnicas produziram os menores tempos médios e as maiores taxas de acerto. Uma última observação importante é que a interação é uma característica muito importante quando se trata de ambientes tridimensionais. Observou-se que a ausência deste aspecto na avaliação por meio de questionários foi um dos fatores que contribuiu para diminuir o desempenho das técnicas apresentadas no domínio 3D.

\section{Conclusões e Trabalhos Futuros}

Este trabalho propôs cinco técnicas de VI com o objetivo de tornar o entendimento de resultados de sistemas de CBIR mais intuitivo, além de explicitar a lógica de classificação das imagens. Um sistema de CBIR foi desenvolvido utilizando como base um sistema previamente desenvolvido. Definidos os critérios de similaridade entre as imagens (os extratores), as técnicas foram implementadas.

No contexto avaliado, as duas técnicas de VI que se mostraram mais eficientes foram as bidimensionais linear e em espiral. As técnicas tridimensionais, em especial a tridimensional em espiral, não foram bem avaliadas devido às dificuldades de navegação e à quantidade menor de informações exibidas na interface principal do sistema implementado.

Considerando os acertos e os erros encontrados nas técnicas propostas, é possível sugerir que, em trabalhos futuros, sejam melhoradas a disposição e a diminuição dos tamanhos das imagens. Isto pode ser feito, por exemplo, utilizando formas não lineares de posicionar e de redimensionar as imagens. A fim de melhorar as visualizações tridimensionais, o sistema poderia ser adaptado para utilizar realidade virtual e também para interagir com dispositivos de entrada que envolvam toques ou captura de movimentos como, por exemplo, luvas interativas e sensores de movimentos.

Apesar de algumas limitações detectadas durante a avaliação com os usuários, todas as técnicas atingiram os objetivos propostos, ou seja, facilitar a compreensão de resultados de CBIR e explicitar o funcionamento desse tipo de sistema. Verifica-se, portanto, que técnicas nos domínios 2D e 3D constituem um importante tópico para ser explorado no contexto de Visualização de Informação, especialmente quando aplicadas à compreensão de resultados de sistemas de CBIR e, por isso, outras técnicas podem ser desenvolvidas e visualizações de resultados de outros sistemas podem ser exploradas.

\section{Referências}

[Bergamasco e Nunes 2011] Bergamasco, L. e Nunes, F. L. S. (2011). Recuperação de imagens por conteúdo utilizando lógica fuzzy - um estudo de caso sobre imagens faciais. In Workshop de Visão Computacional, volume 7. 
[Chan et al. 2014] Chan, Y.-H., Correa, C. D., e Ma, K.-L. (2014). Regression cube: A technique for multidimensional visual exploration e interactive pattern finding. ACM Trans. Interact. Intell. Syst., 4(1):7:1-7:32.

[Chau 2011] Chau, M. (2011). Visualizing web search results using glyphs: Design e evaluation of a flower metaphor. ACM Trans. Manage. Inf. Syst., 2(1):2:1-2:27.

[Datta et al. 2008] Datta, R., Joshi, D., Li, J., e Wang, J. Z. (2008). Image retrieval: Ideas, influences, e trends of the new age. ACM Comput. Surv., vol 40(n 2):5:1-5:60.

[Dias e Carvalho 2007] Dias, M. P. e Carvalho, J. O. F. (2007). A visualização da informação e a sua contribuição para a ciência da informação. DataGramaZero - Revista de Ciência da Informação, vol 8(n 5).

[Dörk et al. 2012] Dörk, M., Williamson, C., e Carpendale, S. (2012). Navigating tomorrow's web: From searching e browsing to visual exploration. ACM Trans. Web, 6(3):13:1-13:28.

[Freitas et al. 2001] Freitas, C. M. D. S., Chubachi, O. M., e Cava, R. A. (2001). Introdução à visualização de informações. Revista de Informática Teórica e Aplicada, vol 8(n 2):143-158.

[Godinho et al. 2007] Godinho, P., Meiguins, B., Goncalves Meiguins, A., Casseb do Carmo, R., de Brito Garcia, M., Hernandez Almeida, L., e Lourenco, R. (2007). Prisma - a multidimensional information visualization tool using multiple coordinated views. In Information Visualization, 2007. IV '07. 11th International Conference, pages 23 -32 .

[Grégio et al. 2009] Grégio, A. R. A., Filho, B. P. C., Montes, A., e Santos, R. (2009). Minicurso: Técnicas de visualização de dados aplicadas à segurança da informação. Simpósio Brasileiro de Segurança da Informação e de Sistemas Computacionais. SBSeg 2009. $9^{\text {a }}$ Edição.

[Heesch 2008] Heesch, D. (2008). A survey of browsing models for content based image retrieval. Multimedia Tools Appl., vol 40(n 2):261-284.

[Hipp et al. 2013] Hipp, M., Mutschler, B., Michelberger, B., e Reichert, M. (2013). A framework for the intelligent delivery e user-adequate visualization of process information. In Proceedings of the 28th Annual ACM Symposium on Applied Computing, SAC '13, pages 1383-1390, New York, NY, USA. ACM.

[Imo et al. 2008] Imo, J., Klenk, S., e Heidemann, G. (2008). Interactive feature visualization for image retrieval. In Pattern Recognition, 2008. ICPR 2008. 19th International Conference on, pages $1-4$.

[Ltifi et al. 2009] Ltifi, H., Ben Ayed, M., Alimi, A., e Lepreux, S. (2009). Survey of information visualization techniques for exploitation in kdd. In Computer Systems e Applications, 2009. AICCSA 2009. IEEE/ACS International Conference on, pages 218 -225 .

[Lyon 2001] Lyon, D. (2001). Java for programmers. Disponível em http://show. docjava.com/book/cgij/backup/ch27.pdf. 
[Nascimento e Ferreira 2005] Nascimento, H. A. D. e Ferreira, C. B. R. (2005). Visualização de Informações - Uma Abordagem Prática, pages 1262-1312. Livro Texto da XXIV Jornada de Atualização em Informática.

[Pinto-Cáceres 2010] Pinto-Cáceres, S. M. (2010). Técnicas de visualização para sistemas de recuperação de imagens por conteúdo. Master's thesis, Universidade Estadual de Campinas.

[Santos 2007] Santos, J. R. G. S. R. (2007). Temas de geometria nos ensinos básico e secundário. Master's thesis, Universidade de Aveiro. Disponível em: http://ria. ua.pt/bitstream/10773/2893/1/2008000864.pdf.

[Somanath et al. 2014] Somanath, S., Carpendale, S., Sharlin, E., e Sousa, M. C. (2014). Information visualization techniques for exploring oil well trajectories in reservoir models. In Proceedings of the 2014 Graphics Interface Conference, GI '14, pages 145-150, Toronto, Ont., Canada, Canada. Canadian Information Processing Society.

[Torres e Falcão 2008] Torres, R. e Falcão, A. X. (2008). Recuperação de imagens baseada em conteúdo. In Workshop de Visão Computacional, volume 4.

[Yang et al. 2014] Yang, H., Li, Y., e Zhou, M. X. (2014). Understand users\&rsquo; comprehension e preferences for composing information visualizations. ACM Trans. Comput.-Hum. Interact., 21(1):6:1-6:30. 